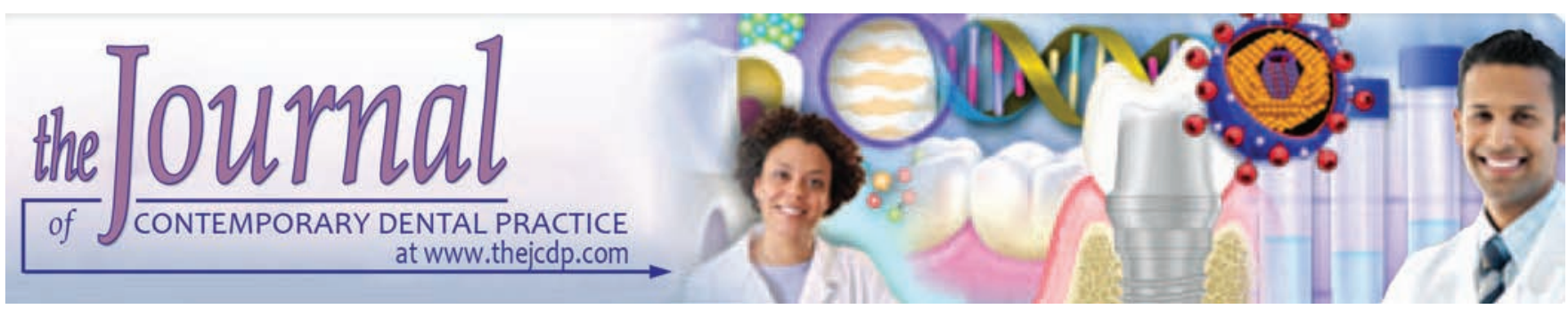

\title{
Effect of Interimplant Distance and Cyclic Loading on the Retention of Overdenture Attachments
}

\author{
${ }^{1}$ Seyed S Shayegh, ${ }^{2}$ Seyed MR Hakimaneh, ${ }^{3}$ Mohammad T Baghani, ${ }^{4}$ Shireen Shidfar, ${ }^{5}$ Farinaz K Kashi \\ ${ }^{6}$ Amirhosein Zamanian, ${ }^{7}$ Ali Arezoobakhsh
}

\section{ABSTRACT}

Aim: The purpose of this in vitro study was to investigate the effect of interimplant distance and cyclic loading on the retention of two locator attachment systems.

Materials and methods: A total of 72 acrylic resin blocks were fabricated and divided into six groups of six pairs each. Locators of DIO and 3i implant systems were positioned on analogs in three different interimplant distances $(19,23$, and $29 \mathrm{~mm})$. The blocks were attached to a universal testing machine, and 1,440 dislodging cycles by the force of $136 \mathrm{~N}$ were applied. After 0 , $120,360,720$, and 1,440 cycles, the retention was recorded. Three-way analysis of variance (ANOVA) was used to test for differences in retention between the various combinations of the locator, interimplant distance, and cyclic loadings.

Results: Interimplant distance was significantly associated with retention, independent of the locator system used, and dislodgement force cycles. Mean retention was significantly higher under the 3 i system relative to the DIO system $(p<0.0001)$. This association varied with both interimplant distance $(p>0.0001)$ and dislodgement force $(p<0.0001)$ as well as across the various combinations of distance and cycle $(p<0.0001)$.

Conclusion: Interimplant distances could affect the initial retention of locator attachments. There was little difference in retention between distances of 23 and $29 \mathrm{~mm}$ across all cycles when both locator systems were combined. Distance of $23 \mathrm{~mm}$ was associated with superior retention in the DIO system. With regard to the speed of retention decrease, the $23 \mathrm{~mm}$ distance was associated with better performance.

Clinical significance: Interimplant distance could play a significant role in overdenture retention with locator attachments.

1,2,3,5-7Department of Prosthodontics, School of Dentistry Shahed University, Tehran, Islamic Republic of Iran

${ }^{4}$ Department of Periodontics, School of Dentistry, Shahed University, Tehran, Islamic Republic of Iran

Corresponding Author: Ali Arezoobakhsh, Department of Prosthodontics, School of Dentistry, Shahed University, Tehran Islamic Republic of Iran, Phone: 00982188959210, e-mail: ali. arezoobakhsh@yahoo.com
Keywords: Dental implants, Dental prosthesis retention, Denture overlay.

How to cite this article: Shayegh SS, Hakimaneh SMR, Baghani MT, Shidfar S, Kashi FK, Zamanian A, Arezoobakhsh A Effect of Interimplant Distance and Cyclic Loading on the Retention of Overdenture Attachments. J Contemp Dent Pract 2017;18(11):1078-1084.

\section{Source of support: Nil}

Conflict of interest: None

\section{INTRODUCTION}

Alveolar ridge resorption is one of the significant conditions associated with loss of stability and retention in mandibular complete dentures, which also decrease the tissue volume available for denture support. ${ }^{1}$ Patients with decreased mandibular support may experience problems with conventional dentures. Some of these problems include pain during mastication and insufficient retention and stability of the dentures. ${ }^{2}$ These problems are more prominent in older patients when adaptive capacities are reduced. ${ }^{3}$ Using conventional complete dentures in these patients will not always result in optimal treatment outcomes. ${ }^{4}$ Therefore, alternatives should be taken into account.

Several studies have shown that poor retention and stability could be managed using a fixed partial denture supported by between five and six implants. ${ }^{5-7}$ However, placing six implants in an atrophic mandible is not always possible. Therefore, the concept of using between two and four implants to support an overdenture is introduced. ${ }^{8}$ According to the McGill consensus, a two-implantsupported overdenture has been accepted as the gold standard of care for the edentulous mandible. ${ }^{9}$ In maladaptive complete denture users, implant-retained overdentures could result in improved masticatory function, patient satisfaction, and improved quality of life compared with complete dentures. ${ }^{10,11}$ 
There are different attachment systems to retain implant-supported overdentures. In one of the major classifications, these attachments are divided into splinted and unsplinted. ${ }^{12}$ Bar attachments are included in splinted systems, whereas unsplinted systems include magnets, ball types, and locators. ${ }^{13}$ Some authors advocate the use of bar-type overdentures; ${ }^{14}$ however, these attachments are more expensive, more complex, and require more restorative space than unsplinted attachments. ${ }^{15,16}$ In patients with a decreased vertical dimension, the freestanding attachment systems are used and are beneficial in terms of initial treatment cost, hygiene, and simplicity of manufacture. ${ }^{12}$

A locator attachment (Zest Anchors, Zest Dental Solutions, Carlsbad, California, USA)introduced to the dental market in 2001 has been used successfully in situations with limited restorative space as a result of its low profile with a height of $3.3 \mathrm{~mm} .{ }^{17-19}$ The "male" part of the locator consists of a metallic housing encompassing replaceable nylon Patrice. The "female" matrix is a cylindrical abutment coated with titanium nitride that has internal and external undercuts. ${ }^{10}$

Different factors contribute to the success of an implant supported overdenture, including the fitness and precision of dentures and the retentive scope of its attachment system to provide long-term functionality. ${ }^{12,20}$ In addition, retention could be one of the most serious factors in determining patient satisfaction. ${ }^{21,22}$

According to Caldwell, ${ }^{23}$ to masticate sticky foods, a distal extension removable partial denture requires a retaining force of 15 to $20 \mathrm{~N}$. For normal foods, this force could be reduced to $10 \mathrm{~N}$. Therefore, to maintain a denture in position, a retentive capacity of 10 to $20 \mathrm{~N}$ is necessary. ${ }^{24}$ The functional masticatory forces in addition to forces generated by the insertion and removal of the overdenture cause micro- and macro-movement between the retentive parts of the attachment and can result in wear and the loss of retention over time. ${ }^{12}$

Various designs of overdenture attachments and different factors that could affect the retention of the attachment have been the subject of previous studies, but the potential impact of different interimplant distances on attachment retention has rarely been investigated. To the best of our knowledge, only two studies ${ }^{25,26}$ have investigated the effect of interimplant distance on attachment retention; however, they did not examine locators. The purpose of this in vitro study was to evaluate the effect of different interimplant distances and cyclic loading on the retentive characteristics of two locator attachment systems. The null hypothesis was that different interimplant distances have no effect on the retention of locator attachments in different cyclic loadings.

\section{MATERIALS AND METHODS}

The experimental design of the study included the fabrication of 36 pairs of acrylic blocks for three interimplant distances $(19,23$, and $29 \mathrm{~mm}$ ) and two brands (DIO and $3 i ; n=6)$. Chaffee et $\mathrm{al}^{27}$ suggested that when designing an overdenture supported by two implants, the canine position is preferred for the placement of fixtures. The three interimplant distances that were used in the present study were selected based on the results of Michelinakis et al, ${ }^{25}$ which investigated 100 complete mandibular dentures and reported that the mean intercanine distance is $22.88 \mathrm{~mm}$.

Two locator attachments (Zest Anchors, Zest Dental Solutions, Carlsbad, California, USA) consisting of the DIO implant system (DIO Co., Busan, Korea) and the 3i implant system (BIOMET 3i, Palm Beach Gardens, Florida, USA) were attached to corresponding implant analogs using a locator tool (Zest Anchors, Zest Dental Solutions, Carlsbad, California, USA). Metal housings containing black processing caps were connected to each corresponding locator.

Two rectangular metallic blocks were fabricated with internal dimension of $35 \times 15 \times 40 \mathrm{~mm}$. Autopolymerizing polymethyl methacrylate resin (GC RELINE, GC America INC, ALSIP, Illinois, USA) was mixed according to the manufacturer's instructions and poured into the first metallic block. After 15 minutes, two pinholes were drilled (Pindex machine; Coltène/Whaledent, Inc, Cuyahoga Falls, Ohio) with a specified distance from each other and identical distances from the edges of the block. The radius of the pinholes was $1 \mathrm{~mm}$ larger than the corresponding metal housing.

One of the attachment assemblies was luted to the dental surveyor analyzing rod (Saeshin Precision Co., Ltd., Dalseong, Korea) using sticky wax (Kerr Corp., West Collins Orange, California, USA) in order that the metal housing positioned downward. It was stabilized in the pinhole by autopolymerizing resin. The second attachment assembly was then placed in the adjacent pinhole in the same manner so that the two assemblies were completely parallel and at the same height (Fig. 1). The parallelism of the two assemblies was rechecked by a surveyor.

The second metallic block was filled with autopolymerizing resin and inverted on implant analogs in the first block. The two blocks were attached to the universal testing machine (Zwick Roell Group, Ulm, Germany) until the resin completely hardened. After setting, the two blocks were separated. One block consisted of locators attached to implant analogs (Block A) and the other block consisted of metal housings (Block B). After the two blocks were separated, the black processing cap in Block B was replaced with a clear nylon insert. 


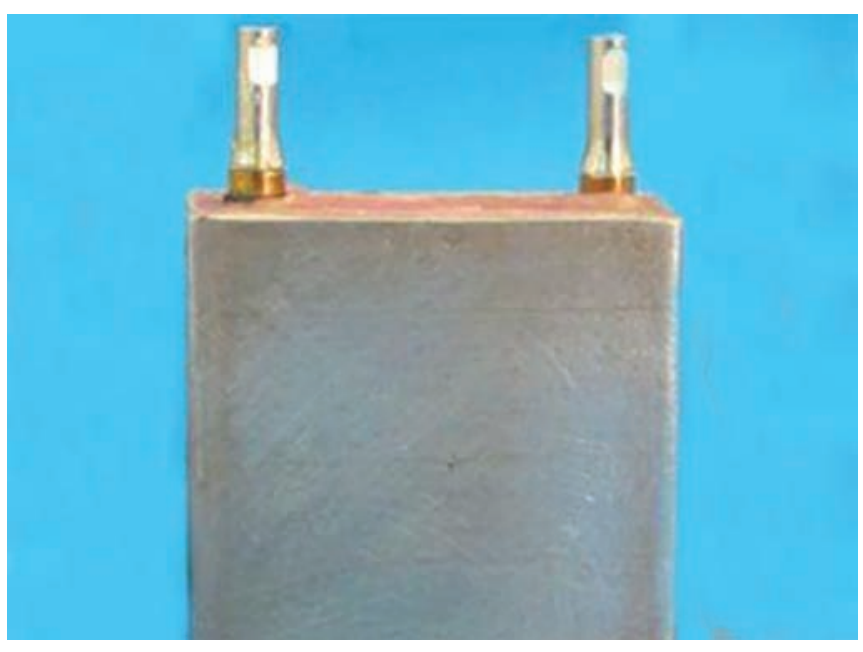

Fig. 1: Resin block with two parallel assemblies

After the completion of attachment insertion, the following six groups were formed: (1) D19: DIO locator with a $19 \mathrm{~mm}$ interimplant distance; (2) D23: DIO locator with a $23 \mathrm{~mm}$ interimplant distance; (3) D29: DIO locator with a $29 \mathrm{~mm}$ interimplant distance; (4) i19: 3i locator with a $19 \mathrm{~mm}$ interimplant distance; (5) i23: 3i locator with a $23 \mathrm{~mm}$ interimplant distance; and (6) i29: 3i locator with a $29 \mathrm{~mm}$ interimplant distance $(n=6)$.

Blocks $\mathrm{A}$ and $\mathrm{B}$ were attached to the lower and upper members of the testing machine respectively. Three pairs of attachments were tested for each of the six groups. Dislodging cycles were applied to the attachment system using the universal testing machine (Zwick Roell Group, Ulm, Germany), which was connected to the personal computer (Asus, ASUSTeK Computer Inc., Taipei, Taiwan). Data collection and analysis of retention reduction were performed with appropriate software (test Xpert machine v10). ${ }^{11}$ Every dislodging cycle was done at $50 \mathrm{~mm} /$ minute speed with the preload of $0.2 \mathrm{~N}$ and the preload speed of $10 \mathrm{~mm} /$ minute.

To determine the relevant rate of dislodging cyclic force applications, a pilot study was carried out. The rate of application of dislodging force (cycles/minute) could probably affect the retention of attachment according to the rubber nature of nylon inserts. When the nylon insert deforms under its elastic modulus limit, it takes a specific time to return to its previous form. If the dislodging force application rate is high, nylon may not have enough time to return to its basic form and may lose retention. In the pilot study, four different speeds $(2,10,20$, and 40 cycles / minute) were used to dislodge the housing from the locator attachment, and the maximum dislodging force in the four groups compared. The results show that in the first three groups, the mean dislodging force was $136 \mathrm{~N}$, and in the fourth, it became less than $100 \mathrm{~N}$. Therefore, by increasing the dislodging rate, the maximum dislodging force was decreased. Accordingly, 20 cycles/minute was selected for the main study.

In normal situations, a patient places/removes an overdenture prosthesis four times each day (in the morning [placement], after breakfast, after lunch, after dinner [removal and replacement], and before bedtime [removal]). ${ }^{28}$ Accordingly, time was determined based on the equation:

\section{Number of cycles/4 = Number of days}

Maximum dislodging force of the attachments was measured after being subjected to 0, 120 (1 month), 360 (3 months), 720 (6 months), and 1,440 (1 year) cycles of removal.

One of the nylon inserts and locator abutments was randomly selected and after 0 and 1,440 dislodging cycles were examined under stereomicroscope (Magnum, Olympus, India Pvt., Ltd., New Delhi, India) at $\times 40$ magnification.

\section{Statistical Analysis}

Continuous variables were summarized using mean and standard deviation (SD). For the primary analysis, a three-way ANOVA was used to test for differences in the primary endpoint (retention) by the locator system, interimplant distance, and cyclic dislodging forces. For each combination of locator, implant distance, and dislodging force, all six replicates were used in the analysis. The replicate number was included in the three-way ANOVA as a grouping variable to permit calculation of the pooled covariance matrix and to adjust the ANOVA for the nonindependence of replicate data. As a secondary analysis, a two-way ANOVA was used to assess differences in retention by both locator system and interimplant distance, separately for each dislodgement force cycle group. Homogeneity of variance across each combination of locator, implant distance, and dislodgement force groups was tested using Levene's test. For the primary analysis, $\mathrm{p}<0.05$ was considered significant. For the secondary analysis, the Bonferroni correction was applied to adjust for multiple comparisons. All analyses were conducted using Statistical Package for the Social Sciences version 22.0 and Stata version 14 (StataCorp, College Station, Texas, USA).

\section{RESULTS}

The mean and SD of retention for DIO and 3i implant systems after each cycle are shown in Graphs 1 and 2 respectively. Overall, mean retention was significantly higher under the $3 \mathrm{i}$ locator system relative to DIO system $(p<0.0001)$. This association varied with both interimplant distance (locator / distance two-way interaction $\mathrm{p}>0.0001$ ) and dislodgement force (locator / cycle 


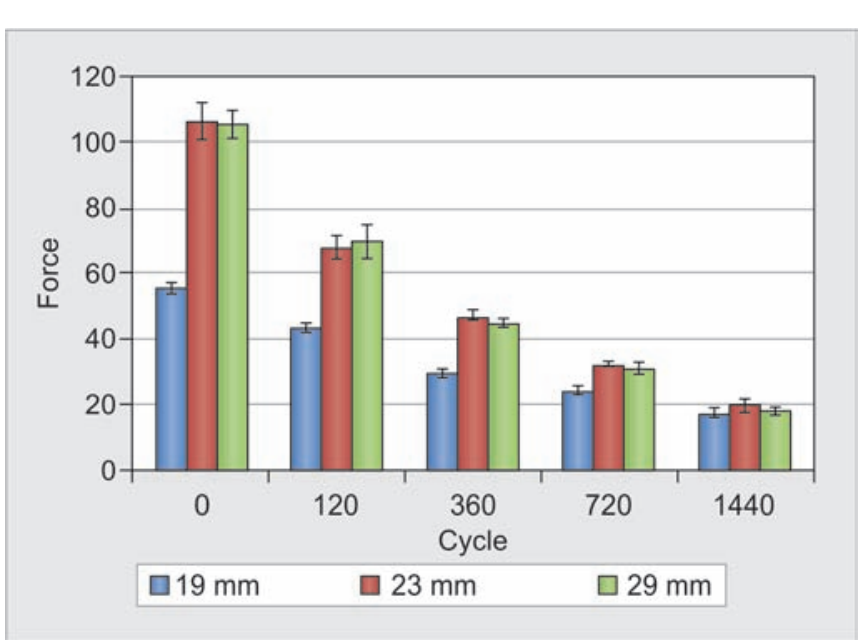

Graph 1: The mean and SD of retention for DIO implant system after $0,120,360,720$, and 1,440 dislodging cycles

two-way interaction $\mathrm{p}<0.0001)$, as well as across the various combinations of distance and cycle (locator/ distance/cycle three-way interaction $\mathrm{p}<0.0001)$. The full results of the three-way ANOVA are detailed in Table 1.

Initial retention across both locator systems combined (dislodgement cycles $=0$ ) was maximized at an interimplant distance of $29 \mathrm{~mm}$ (mean 44.3, SD 10.5), which was greater than that observed using a distance of $23 \mathrm{~mm}$ (mean 40.3, SD 8.2) and considerably in excess of the retention observed using an interimplant distance of $19 \mathrm{~mm}$ (mean 21.4, SD 6.1). Across all dislodgement cycles, a similar pattern was observed, albeit less marked than the initial retention. Retention was again maximal at $29 \mathrm{~mm}$ across both locator systems combined (mean 22.4, SD 6.1), marginally ahead of $23 \mathrm{~mm}$ (mean 22.1, SD 14.1) and almost twice the magnitude of the retention observed at $19 \mathrm{~mm}$ (mean 12.2, SD 6.1). Retention was significantly higher under the $3 i$ locator for all three interimplant distances, relative to the DIO system and independent of the dislodgement force (Table 2). For both locator systems, retention was maximized using the 23 $\mathrm{mm}$ interimplant distance (mean retention $\mathrm{DIO}=17.87$; $3 i=26.27$ ). However, the difference in retention between the two locator systems was maximized at an interimplant

Table 1: Three-way factorial ANOVA (outcome = retention)

\begin{tabular}{lllll}
\hline Source & Partial SS & $d f$ & $F$ & $p$-value \\
\hline Model & 24948.84 & 29 & 97.19 & $<0.0001$ \\
Locator & 1819.29 & 1 & 205.52 & $<0.0001$ \\
Interimplant distance & 3764.81 & 2 & 212.65 & $<0.0001$ \\
Dislodgement force cycle & 16137.55 & 4 & 455.76 & $<0.0001$ \\
Locator distance & 347.97 & 2 & 19.65 & $<0.0001$ \\
Locator cycle & 548.66 & 4 & 15.50 & $<0.0001$ \\
Distance cycle & 1849.74 & 8 & 26.12 & $<0.0001$ \\
Locator distance cycle & 239.19 & 8 & 3.38 & 0.0014 \\
\hline
\end{tabular}

$\mathrm{SS}=$ Sum of squares; $\mathrm{df}=$ degree of freedom.

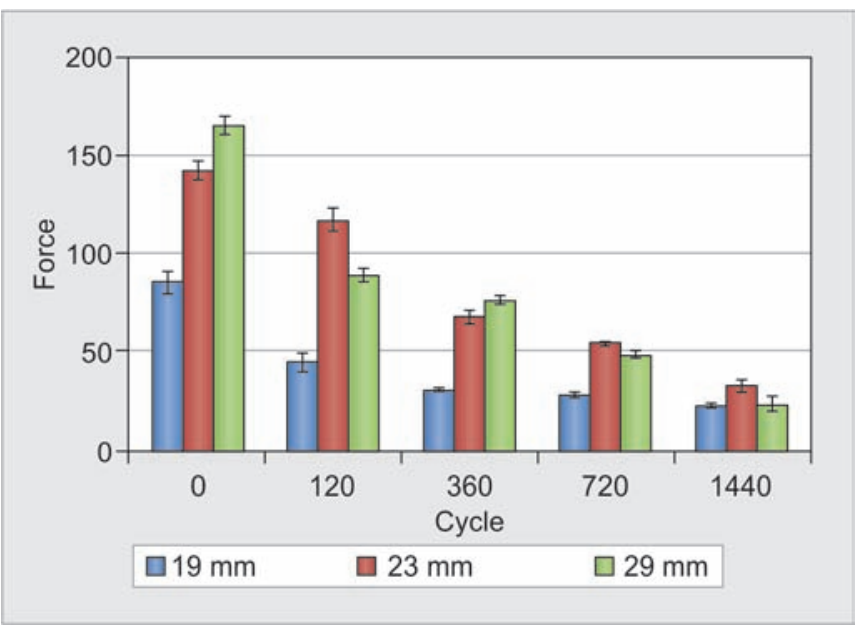

Graph 2: The mean and SD of retention for 3i implant system after $0,120,360,720$, and 1,440 dislodging cycles

distance of $29 \mathrm{~mm}(\mathrm{DIO}=17.52 ; 3 \mathrm{i}=26.01)$. This was consistent across all dislodgement cycles.

Retention was significantly higher under the $3 i$ locator for all dislodgement force cycles with the exception of the 1,440 cycles (simulating 12 months of wear), independent of the interimplant distance (Table 3). The difference in retention between locator systems was greatest under zero cycles that simulated zero month of clinical use (mean retention DIO $=28.15$ vs $3 \mathrm{i}=41.59$ ). This difference between the locator systems became progressively smaller with increasing dislodgement force (representing increasing clinical use from 0 through 12 months). Initial retention (zero dislodgement cycles) was maximized at an interimplant distance of $29 \mathrm{~mm}$ for the $3 \mathrm{i}$ locator. By comparison, an interimplant distance of $23 \mathrm{~mm}$ returned maximal initial retention using the DIO locator. The difference in initial retention between the two locator systems,

Table 2: Two-way factorial ANOVA (outcome = retention; explanatory variables $=$ locator and dislodgement force)

\begin{tabular}{lll}
\hline $\begin{array}{l}\text { Interimplant } \\
\text { distance }(\mathrm{mm})\end{array}$ & $\begin{array}{l}\text { Locator cycle } \\
\text { interaction } F\end{array}$ & $\begin{array}{l}\text { Locator cycle } \\
\text { interaction } p \text {-value* }\end{array}$ \\
\hline 19 & 5.32 & 0.0012 \\
23 & 3.20 & 0.0204 \\
29 & 17.64 & $<0.0001$ \\
\hline
\end{tabular}

*Bonferroni adjusted

Table 3: Two-way factorial ANOVA (outcome = retention; explanatory variables $=$ locator and implant distance)

\begin{tabular}{llll}
\hline $\begin{array}{l}\text { Dislodgement } \\
\text { force (cycles) }\end{array}$ & Months & $\begin{array}{l}\text { Locator } \\
\text { distance } \\
\text { interaction } F\end{array}$ & $\begin{array}{l}\text { Locator distance } \\
\text { interaction } \\
p \text {-value* }\end{array}$ \\
\hline 0 & 0 & 3.98 & 0.0297 \\
120 & 1 & 6.99 & 0.0033 \\
360 & 3 & 30.93 & $<0.0001$ \\
720 & 6 & 17.62 & $<0.0001$ \\
1440 & 12 & 0.68 & 0.5123 \\
\hline
\end{tabular}

*Bonferroni adjusted 


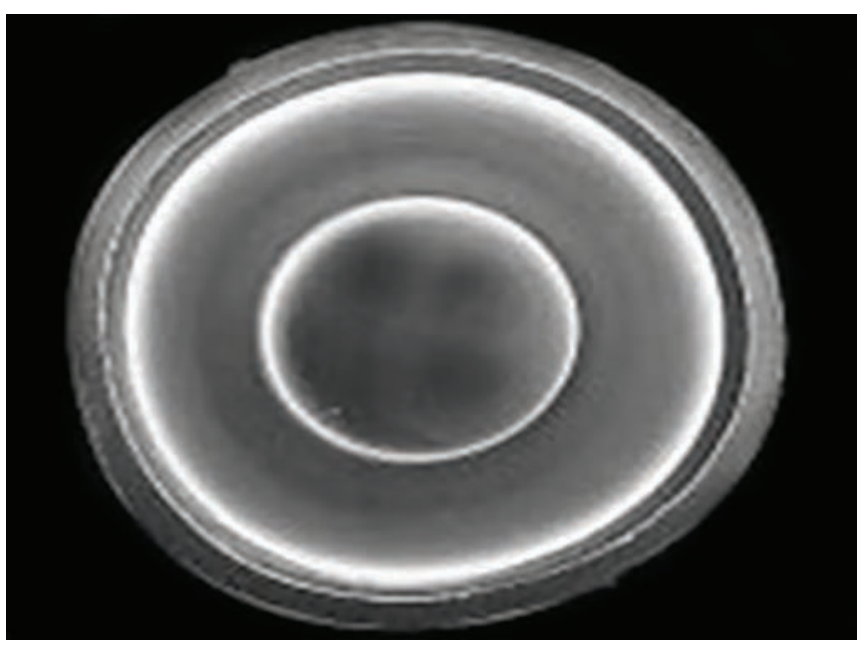

Fig. 2: Stereomicroscope picture of nylon insert after 0 dislodging cycles (40x)



Fig. 4: Stereomicroscope picture of locator attachment after 0 dislodging cycles $(\times 40)$

favoring $3 \mathrm{i}$, was maximized at an interimplant distance of $29 \mathrm{~mm}$. Evaluation of nylon inserts under stereomicroscope after 0 and 1,440 cycles of wear simulation (Figs 2 and 3) revealed partial deformation of nylon insert after 1,440 cycles, whereas the locator abutment after 0 and 1,440 cycles (Figs 4 and 5) does not show obvious surface alterations.

\section{DISCUSSION}

This in vitro study investigating the effect of different interimplant distances and cyclic dislodgement on the retentive properties of two brands of locator attachments suggests that different interimplant distances are associated with significant differences in locator attachment retention, independent of cyclic dislodgement. The present study describes the retentive behavior of locator attachments both before and after cyclic dislodgement at different interimplant distances. The existing evidence base describing retention differentials across interimplant differences is limited, with the majority of the precedent



Fig. 3: Stereomicroscope picture of nylon insert after 1,440 dislodging cycles $(\times 40)$

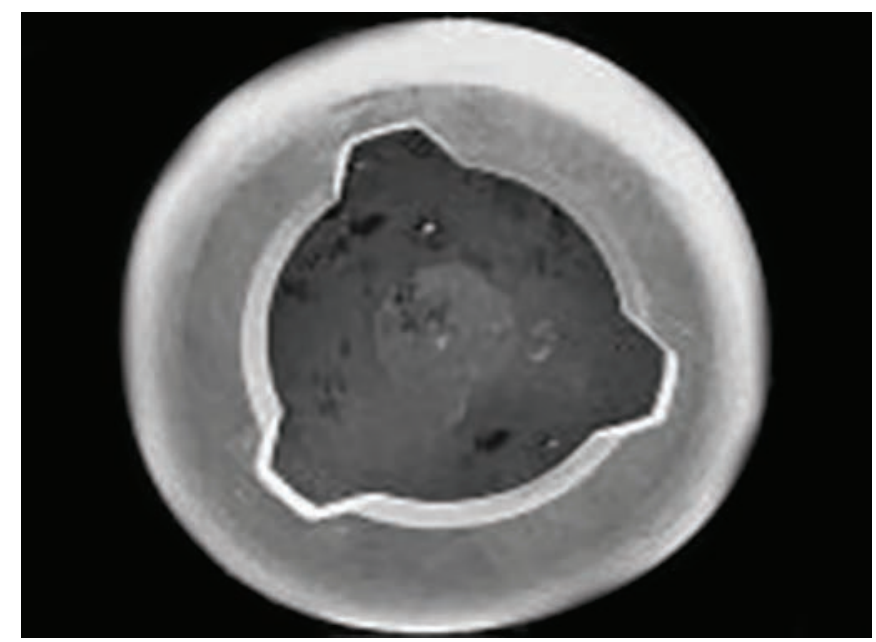

Fig. 5: Stereomicroscope picture of locator attachment after 1,440 dislodging cycles $(\times 40)$

literature focusing on the retentive characteristics of locators on arbitrary or fixed interimplant distances only. ${ }^{4,20,22}$ Only a single study has described the effect of interimplant distance on the retentive features of attachment systems ${ }^{25}$; however, this study did not investigate the influence of the locator attachment itself.

The results of the present study demonstrated that interimplant distance was associated with the initial retention of $3 \mathrm{i}$ locator attachments. Increasing the distance from 19 to $23 \mathrm{~mm}$, and from 23 to $29 \mathrm{~mm}$, significantly increased the initial retention. In the DIO group, the initial retention of locator attachments was significantly higher with increasing interimplant distance, which caused rejection of our null hypothesis. As the locators of the two implant systems used in this study were geometrically different, and the nylon inserts were the same, this observed difference may be related to the geometry of the locator attachments.

Conversely, while the initial retention of the $3 i$ locator attachments was higher at the $29 \mathrm{~mm}$ interimplant distance, 
retention after 120 cycles (as a proxy for 1 month of clinical use) rapidly decreased so that retention becomes lower relative to the $23-\mathrm{mm}$ interimplant distance. However, the difference between the retention of $3 \mathrm{i}$ attachments in 23 and $29 \mathrm{~mm}$ interimplant distances was not significant after 360,720 , and 1,440 cycles. Taken together, these results suggest that while increasing the interimplant distance from 23 out to $29 \mathrm{~mm}$ may result in higher initial retention, it may actually accelerate the speed of subsequent loss of retention. This may be secondary to the increased retention produced by nylon caps, the reaction force to caps and their deformation also increased; therefore, they deteriorate more rapidly as the retention decreases.

Across both implant systems, retention after 0, 120, 360 , and 720 cycles was significantly higher using the $23 \mathrm{~mm}$ interimplant distance relative to the $19 \mathrm{~mm}$ distance. However, no significant difference between the two distances was observed after 1,440 cycles across both locator systems, likely due to degradation of nylon caps (Fig. 5).

These results suggest that initial retention is higher using the DIO implant system and that an interimplant distance of $23 \mathrm{~mm}$ outperforms the $29 \mathrm{~mm}$ distance. Similarly, the $23 \mathrm{~mm}$ interimplant distance also outperformed $19 \mathrm{~mm}$ with regard to superior retention after 720 dislodgement cycles in both the $3 \mathrm{i}$ and DIO implant systems. In contrast to our study, Michelinakis et $\mathrm{al}^{25}$ in their study on the influence of different interimplant distances on initial retention of stud and bar type attachments reported that initial retention of the stud attachment increased as interimplant distance moved out from 19 to $23 \mathrm{~mm}$ and from 23 to $29 \mathrm{~mm}$ interimplant distances. However, these results were not statistically significant. Furthermore, the stud attachments used in the Michelinakis et al study were ball type, unlike the present study.

Rutkunas et $\mathrm{al}^{22}$ investigated the wear characteristics of different attachment systems reported that locator attachments lost their initial retention between 21 and $62 \%$ after 15,000 cycles of wear simulation. Based on scanning electronic microscope analysis, the authors concluded that the wear of nylon inserts may be partially responsible for the decreasing retention observed. Similarly, in the present study, the retention decreased significantly after 1,440 cycles in all groups. This could be related to partial deformation of nylon insert after 1,440 cycles of wear simulation (Fig. 3). These findings are consistent with Kobayashi et $\mathrm{al}^{12}$ who reported similar results after 14,600 dislodgement cycles.

Overall, the studies on the effect of interimplant distance on locator retention are limited. Comparisons can only be performed with studies that have reported the interimplant distance in their study protocol. Uludag et $\mathrm{al}^{20}$ reported consistently lower mean initial retentive values for locator attachments with an interimplant distance of $22 \mathrm{~mm}$ compared with all interimplant distances in the present study. As the manufacturer of locator attachment used in that study was different, the difference may be associated with different geometry of the locators used.

Some of the authors investigated the influence of interimplant distance on clinical aspects of two implant overdentures. ${ }^{11,29}$ Marin et $\mathrm{al}^{11}$ reported that in two implant overdenture cases with more than $22 \mathrm{~mm}$ interimplant distance, the deactivation of matrices was more common than the distance $<22 \mathrm{~mm}$. These findings are partially in compliance with the result of the present study, as 3i locator attachments $29 \mathrm{~mm}$ apart lose their retention more rapidly than other groups.

In the study conducted by Geckili et al, ${ }^{29}$ the influence of interimplant distance on oral health impact profile-14 (OHIP-14) of patients using two implant overdentures were analyzed. They failed to find a positive relationship between OHIP-14 total and interimplant distance. Comparing the results of this study, we could discuss that although the $23 \mathrm{~mm}$ interimplant distance has better retention performance in our in vitro study, in vivo, different interimplant distances do not play a significant role in the quality of life of patients.

Different factors affect the retention of attachments, such as number and position of implants, the overdenture design, and the material and type of attachment. It is also important to notice that during function, different forces in different directions are applied on attachments. In the present study, unlike in vivo, only the fatigue of attachments during insertion and removal was surveyed, which is a limitation of this study. Another important factor that affects attachment fatigue in vivo is the presence of saliva, which was not simulated in the present study. Further investigations that use artificial saliva and greater implant numbers are indicated to draw distinct conclusions.

\section{CONCLUSION}

Interimplant distance is associated with retention independent of both the specific locator system used and the cyclic dislodgement force applied. Retention decreases significantly after 1,440 dislodgment cycles. While an interimplant distance of $29 \mathrm{~mm}$ appears to be optimal when considering both locator systems combined, $23 \mathrm{~mm}$ is associated with the greatest retention using the DIO implant system. The distance of $23 \mathrm{~mm}$ was also associated with better performance with regard to the speed of retention decrease.

\section{REFERENCES}

1. Redford M, Drury TF, Kingman A, Brown LJ. Denture use and the technical quality of dental prostheses among persons 
18-74 years of age: United States, 1988-1991. J Dent Res 1996 Feb;75 Spec No:714-725.

2. van Waas MA. The influence of clinical variables on patients' satisfaction with complete dentures. J Prosthet Dent 1990 Mar;63(3):307-310.

3. Polzer I, Schimmel M, Müller F, Biffar R. Edentulism as part of the general health problems of elderly adults. Int Dent J 2010 Jun;60(3):143-155.

4. Chung KH, Chung CY, Cagna DR, Cronin RJ Jr. Retention characteristics of attachment systems for implant overdentures. J Prosthodont 2004 Dec;13(4):221-226.

5. Adell R, Lekholm U, Rockler B, Brånemark PI. A 15-year study of osseointegrated implants in the treatment of the edentulous jaw. Int J Oral Surg 1981 Dec;10(6):387-416.

6. Albrektsson T. A multicenter report on osseointegrated oral implants. J Prosthet Dent 1988 Jul;60(1):75-84.

7. Adell R, Eriksson B, Lekholm U, Brånemark PI, Jemt T. Long-term follow-up study of osseointegrated implants in the treatment of totally edentulous jaws. Int J Oral Maxillofac Implants 1990 Winter;5(4):347-359.

8. Stellingsma C, Vissink A, Meijer HJ, Kuiper C, Raghoebar GM. Implantology and the severely resorbed edentulous mandible. Crit Rev Oral Biol Med 2004 Jul 1; 15(4): 240-248.

9. White GS. Treatment of the edentulous patient. Oral Maxillofac Surg Clin North Am 2015 May;27(2):265-272.

10. Stephens GJ, di Vitale N, O'Sullivan E, McDonald A. The influence of interimplant divergence on the retention characteristics of locator attachments, a laboratory study. J Prosthodont 2014 Aug;23(6):467-475.

11. Marin M, Tandara A, Preoteasa E. Correlations between interimplant distance and clinical aspects in two implant mandibular overdentures. Implantology 2011 Jul-Sep;1(3):304-309.

12. Kobayashi M, Srinivasan M, Ammann P, Perriard J, Ohkubo C, Müller F, Belser UC, Schimmel M. Effects of in vitro cyclic dislodging on retentive force and removal torque of three overdenture attachment systems. Clin Oral Implants Res 2014 Apr;25(4):426-434.

13. Naert I, Gizani S, Vuylsteke M, Van Steenberghe D. A 5-year prospective randomized clinical trial on the influence of splinted and unsplinted oral implants retaining a mandibular overdenture: prosthetic aspects and patient satisfaction. J Oral Rehabil 1999 Mar;26(3):195-202.

14. Misch C. Contemporary implant dentistry. 3rd ed. St. Louis: Elsevier; 2008.

15. Sadowsky SJ. Mandibular implant-retained overdentures: a literature review. J Prosthet Dent 2001 Nov;86(5):468-473.

16. Burns DR. Mandibular implant overdenture treatment: consensus and controversy. J Prosthodont 2000 Mar;9(1):37-46.
17. Ahuja S, Cagna DR. Classification and management of restorative space in edentulous implant overdenture patients. J Prosthet Dent 2011 May;105(5):332-337.

18. Pasciuta M, Grossmann Y, Finger IM. A prosthetic solution to restoring the edentulous mandible with limited interarch space using an implant-tissue-supported overdenture: a clinical report. J Prosthet Dent 2005 Feb;93(2):116-120.

19. Lee CK, Agar JR. Surgical and prosthetic planning for a twoimplant-retained mandibular overdenture: a clinical report. J Prosthet Dent 2006 Feb;95(2):102-105.

20. Uludag B, Polat S. Retention characteristics of different attachment systems of mandibular overdentures retained by two or three implants. Int J Oral Maxillofac Implants 2012 Nov-Dec;27(6):1509-1513.

21. Ortegón SM, Thompson GA, Agar JR, Taylor TD, Perdikis D. Retention forces of spherical attachments as a function of implant and matrix angulation in mandibular overdentures: An in vitro study. J Prosthet Dent 2009 Apr;101(4):231-238.

22. Rutkunas V, Mizutani H, Takahashi H, Iwasaki N. Wear simulation effects on overdenture stud attachments. Dent Mater J 2011 Jan;30(6):845-853.

23. Caldwell RC. Adhesion of foods to teeth. J Dent Res 1962 Jul-Aug;41:821-832.

24. Walmsley AD, Frame JW. Implant supported overdentures the Birmingham experience. J Dent 1997 Jan;25 Suppl 1: S43-S47.

25. Michelinakis G, Barclay CW, Smith PW. The influence of interimplant distance and attachment type on the retention characteristics of mandibular overdentures on 2 implants: initial retention values. Int J Prosthodont 2006 Sep-Oct;19:507-512.

26. Doukas D, Michelinakis G, Smith PW, Barclay CW. The influence of interimplant distance and attachment type on the retention characteristics of mandibular overdentures on 2 implants: 6-month fatigue retention values. Int J Prosthodont 2008 Mar-Apr;21(2):152-154.

27. Chaffee NR, Felton DA, Cooper LF, Palmqvist U, Smith R. Prosthetic complications in an implant-retained mandibular overdenture population: initial analysis of a prospective study. J Prosthet Dent 2002 Jan;87(1):40-44.

28. Al-Ghafli SA, Michalakis KX, Hirayama H, Kang K. The in vitro effect of different implant angulations and cyclic dislodgement on the retentive properties of an overdenture attachment system. J Prosthet Dent 2009 Sep;102(3):140-147.

29. Geckili O, Cilingir A, Erdogan O, Kesoglu A, Bilmenoglu C, Ozdiler A, Bilhan $\mathrm{H}$. The influence of inter-implant distance in mandibular overdentures supported by two implants on patient satisfaction and quality of life. Int J Prosthodont 2015 Jan-Feb;28(1):19-21. 